\title{
Gabriela Mistral: Uma trajetória intelectual
}

\author{
Ana Amelia de Moura Cavalcante de Melo ${ }^{1}$
}

\begin{abstract}
Resumo: Este artigo visa a analisar as visões elaboradas pela escritora chilena Gabriela Mistral relativas às questões sociais no Chile nos primeiros anos do século $\mathrm{XX}$ e sua militância como educadora. A partir de 1904, com dezesseis anos, e ainda utilizando seu nome verdadeiro, Lucila Godoy, começou a publicar em diversos jornais na América Latina, assumindo um papel ativo frente aos problemas sociais e políticos de seu país e do continente. Questões relativas ao papel da mulher e à educação popular, questão agrária e indígena, foram discutidas pela escritora ao longo de sua trajetória intelectual. Em 1945, sua produção poética se torna conhecida internacionalmente após receber o Prêmio Nobel de Literatura. Neste estudo, pretende-se examinar essas ideias nos escritos, especialmente jornalísticos, produzidos pela poetisa chilena nos anos anteriores ao recebimento do Nobel e seu ativo papel de educadora, destacando sua atuação enquanto intelectual criadora e mediadora.
\end{abstract}

Palavras-chave: Gabriela Mistral; trajetória intelectual; questões sociais; Chile.

\section{Gabriela Mistral: an intellectual trajectory}

Abstract: This article aims to analyze the views elaborated by the Chilean writer Gabriela Mistral on social issues in Chile in the early years of the twentieth century and her militancy as an educator. From 1904, at the age of sixteen, Lucila Godoy began publishing in several newspapers in Latin America, taking an active role in face of the social and political problems of her country and the continent. Issues related to the role of women and popular education, agrarian and indigenous issues, were discussed by the writer throughout her intellectual trajectory. In 1945 his poetic production became internationally known after receiving the Nobel Prize for Literature. This study intends to examine these ideas in the writings, especially journalistic, produced by the Chilean poet in the years before receiving the Nobel and its active role of educator, highlighting her role as creative and mediating intellectual.

Keywords: Gabriela Mistral; intellectual trajectory; social question; Chile.

Artigo recebido em: 28/11/2016

Artigo aprovado em: 18/11/2017

\footnotetext{
1 Professora do Departamento de História da Universidade Federal do Ceará (UFC), Brasil, e do Programa de Pós-graduação em História Social. E-mail: anameliademelo@gmail.com
}

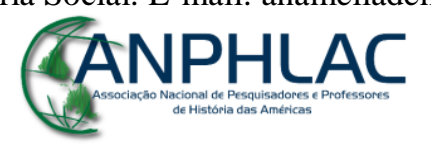

Revista Eletrônica da ANPHLAC, ISSN 1679-1061, №. 24, p. 354-373, Jan./Jun., 2018.

http://revista.anphlac.org.br 


\section{Introdução}

Em nota, acompanhada de foto, o Jornal do Brasil apresentou a chamada com o título: Gabriela Mistral, cidadã da América. ${ }^{2}$ Pretende-se, neste artigo, analisar o significado dessa afirmação à luz dos temas mais frequentes em seus textos jornalísticos e de sua trajetória intelectual. O título de cidadã da América não é desprovido de sentido se considerada toda a trajetória e ativismo dessa intelectual chilena, seja ocupando cargos de Cônsul no Brasil, seja simplesmente como poetisa, especialmente como educadora. Em 1940, quando lhe atribuem o título de cidadã da América, não apenas havia percorrido diversas regiões do Chile, como também do México, Argentina, Cuba e a região do Caribe. Ela escreve e atua intelectualmente em defesa da cultura e autonomia desses países, preocupada especialmente com os povos indígenas, o mundo rural e a mulher.

Em 1929, o então ex-ministro e ex-deputado chileno Pedro Aguirre Cerda ${ }^{3}$ publicou o livro intitulado El Problema Agrário. Exilado na Europa, em consequência das perseguições políticas desencadeadas na ditadura de Ibañez del Campo (19271931), Aguirre Cerda escreveu uma extensa dedicatória à sua amiga e professora Lucila Godoy. A dedicatória considerava a jovem poetisa, já conhecida como Gabriela Mistral, como a fonte de inspiração do livro. Foi com ela que discutiu intensamente os problemas econômicos e sociais do Chile e veio dela a ênfase no problema agrário e a insistência na importância da criação de escolas rurais. Não é possível afirmar com exatidão a data em que se conheceram, porém, sua amizade mantém-se com recíproco respeito e uma intensa troca epistolar. Foi a Aguirre Cerda e à sua esposa que Mistral dedicou seu primeiro livro de poemas Desolación, publicado em 1922 (DOMINGUÉZ, 2002, p. 1).

A dedicatória demonstra a relevância das preocupações sociais dessa professora e poetisa ainda pouco conhecida do grande público. Dizia a dedicatória:

\footnotetext{
${ }^{2}$ Jornal do Brasil, dois de fevereiro de 1940, p. 6.

${ }^{3}$ Pedro Aguirre Cerda (1879-1941). Foi importante político chileno, militante do Partido Radical. Iniciou sua carreira política como deputado, entre 1915 a 1921, e senador no período de 1921-1927. Também foi ministro de Justiça e Instrução Pública em 1918 no governo de Juan Luis Sanfuentes. Dois anos depois, ocuparia a pasta do Ministério do Interior, no primeiro governo de Arturo Alessandri Palma. Com o golpe Militar de 1924, renuncia e se exila na Europa até 1930. Em 1937, foi candidato à Presidência do Chile, sendo eleito em 1938 pela Frente Popular, união dos partidos Socialistas, Comunistas e Radical. Morreu ainda no exercício do cargo em novembro de 1941.
}

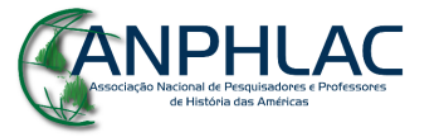

Revista Eletrônica da ANPHLAC, ISSN 1679-1061, №. 24, p. 354-373, Jan./Jun., 2018.

http://revista.anphlac.org.br 


\begin{abstract}
Señorita Lucila Godoy (Gabriela Mistral)
Mi distinguida amiga:

Permítame dedicarle este trabajo que ud. ha inspirado.

Al hablar en Chile sobre la forma de levantarnos espiritual y económicamente, estuvimos conformes en que había que empezar la tarea por la clase agrícola, que tan abnegadamente desempeña la función matriz en el desenvolvimiento colectivo y fundar la escuela rural. Y me agregó Ud. que si reuníamos los recursos necesarios dirigiría Ud. misma una escuela campesina que llevara el nombre de ese noble argentino, Domingo Faustino Sarmiento. [...]

Para solicitar esos recursos a mi regreso al país y fundar el Centro agrícola Sarmiento, he escrito esta obra cuyo íntegro beneficio se dedicará al mismo fin.

Acepte, mi buena amiga, este recuerdo como el esfuerzo primero que hago por realizar sus aspiraciones. [...]. (CERDA, 1929, p. 8)
\end{abstract}

No ano da publicação do livro de Aguirre Cerda, Gabriela Mistral tinha bastante notoriedade por seu trabalho de educadora. Em 1918, ela havia sido nomeada pelo Ministério de Instrução Pública, sob a firma de Aguirre Cerda, para Diretora do Liceu de Meninas Sara Braun de Punta Arenas, primeira escola de educação secundária para meninas na região de Magalhães, no sul do Chile. Em 1920, também é enviada para organizar o Liceu de Temuco, e, em 1921, para o Liceu n. 6 de Santiago. Foi um período inteiramente dedicado a um cuidadoso trabalho. Em Punta Arenas, exercia o cargo de diretora do Liceu, ocasião em que cria o curso noturno para mulheres adultas, fomenta a criação de uma biblioteca, além de realizar diversas palestras enfatizando a importância da educação da mulher. O reconhecimento de seu trabalho a leva a Temuco para também dirigir o liceu de meninas da região.

Seu trabalho de educadora era exercido em paralelo à permanente atividade de escrita. Nesse período, Gabriela Mistral continuou a escrever e publicar artigos e poesias em distintos jornais e revistas chilenas e estrangeiras. Mistral colabora, nessa etapa no Chile, com os jornais El Mercúrio, Diário Ilustrado, com as revistas culturais Atenea, Estudios, Política y Espírito. No continente, publica na revista El Maestro, do México, Repertório Americano, da Costa Rica, Revista América, de Cuba (ARAYA, 2000, p. 45).

Junto a esses escritos, dedicou-se abundantemente a redigir cartas com as quais podia comunicar-se com intelectuais e editores de seu interesse e para os quais enviava seus textos e poesias. Foi através dessa troca que conheceu José de Vasconcelos, quem a convidou a ir ao México em 1922 desenvolver atividades relativas à educação no

\title{
CANPHLAC
}

Revista Eletrônica da ANPHLAC, ISSN 1679-1061, №. 24, p. 354-373, Jan./Jun., 2018.

http://revista.anphlac.org.br 
campo. Foi ele que também, em 1921, fundou a revista El Maestro. A publicação, que levava o subtítulo de Revista de cultura nacional, era mantida pelo Estado mexicano como parte do projeto vasconcelista de educação, ${ }^{4}$ e nela Mistral publicou, naquele mesmo ano, diversos poemas e texto (GARCÍA REY, S/D, p. 2).

No Brasil, sua poesia e seus textos eram também conhecidos entre escritores atentos e interessados na literatura de nossos vizinhos. Mário de Andrade afirma ter conhecido a poetisa chilena em 1925 quando esta foi a São Paulo pela primeira vez a passeio. Posteriormente, em 1940, Mário de Andrade escreve um artigo no Estado de São Paulo que revela um conhecimento de sua poesia e de suas preocupações. As palavras de Mário de Andrade permitem identificar a construção de laços de uma geração orientada por motivações políticas e sociais. Especificamente, Mistral irá se preocupar com a educação e a difusão da leitura. Mário de Andrade chama a atenção para a preocupação da escritora com os destinos do continente, com a identificação de uma cultura e natureza da América: "Nós participávamos em pouco tempo de sua intimidade [...] a quem ela proporcionava um pouco de sua grandeza", dizia Mário de Andrade. "Ouvindo-a falar eu me sentia mexicano [...]. Gabriela Mistral se integrava em sua América principalmente pelo México tradicional” (PIZARRO, 2005, p. 103). Nesse período, entre os anos 1940 e 1945, Gabriela Mistral atuava no Brasil como Cônsul do Chile. A premiação do Nobel em 1945 foi a celebração não só de sua trajetória pessoal, mas também, simbolicamente, a coroação de uma escrita da América, conforme dizia a imprensa brasileira. Em 1940, o embaixador do Chile Mariano Fontecilla falou ao Jornal do Brasil sobre a candidata ao Prêmio Nobel de 1940, tecendo elogios à sua trajetória como educadora e poetisa. ${ }^{5}$ A Academia Brasileira de Letras junta-se à campanha, indicando por unanimidade seu nome para o prêmio, bem como o Instituto Histórico Geográfico Brasileiro.

Diante da abundância de material produzido pela escritora chilena, detenho-me aqui nos escritos na fase de juventude e anterior ao recebimento do Prêmio Nobel. As fontes utilizadas neste estudo estão disponíveis em publicações de coletâneas e

\footnotetext{
4 Entre 1921 e 1924, José Vasconcelos foi Ministro de Educação do governo de Álvaro Obregón, iniciando um projeto cultural-educativo que incluía uma intensa campanha de alfabetização, criação de bibliotecas, escolas rurais, etc. Ver: CRESPO, Regina. O projeto educativo de José Vasconcelos no México pós-revolucionário: nacionalismo e modernidade. Intellèctus, Ano XV, n. 2, Rio de Janeiro, 2016. ${ }^{5}$ Gabriela Mistral foi candidata ao Prêmio Nobel de Literatura de 1940, porém só foi premiada em 1945.
} 
compilações citadas em referências. ${ }^{6}$ Nesse momento, escrevia e ensinava para viver da remuneração por essas atividades (TEITELBOIM, 1991, p. 142).

Ao pretender discutir a escrita e trajetória de uma intelectual, neste estudo, farse-á uso da noção de intelectual proposta por Sirinelli (2003, p. 242). O intelectual é entendido como produtor e mediador de interpretações sobre a realidade. A acepção, ainda que de contornos variáveis, é útil se precisados os termos de sua definição. A historiografia tem situado o nascimento da categoria de intelectual na França, a partir do caso Dreyfus em 1898-1899, no manifesto de Émile Zola. Sua história está associada à noção de intelectual engajado que faz uso de sua especialização e notoriedade ou, conforme afirma Bourdieu, do "capital simbólico" que possui para a defesa de uma causa (2009). Trata-se, no caso em estudo, de examinar a trajetória da escritora a partir de sua intervenção no debate público, legitimada pelo reconhecimento social de sua escrita. Por sua vez, a noção de trajetória busca distanciar-se de uma perspectiva de desígnio estabelecido e ordenado, tal como nos alerta Bourdieu sobre a ilusão biográfica (1998). A noção de trajetória privilegia as relações do indivíduo com o meio em que atua e seu contexto histórico.

\section{Gabriela Mistral: a construção de uma trajetória intelectual}

A produção poética da escritora chilena, prêmio Nobel de literatura em 1945, tem merecido a atenção de diversos pesquisadores, especialmente chilenos. ${ }^{7}$ Por sua vez, a vasta produção de textos considerados políticos escritos por Mistral ocupa um lugar secundário nos exames de sua obra, ainda que estes representem uma importante contribuição para a compreensão de sua literatura como um todo.

Nascida no norte do Chile, num pequeno povoado no Valle del Elqui em 1889, Lucila de María del Perpétuo Socorro Godoy Alcayaga, logo cedo, inicia sua escrita

\footnotetext{
${ }^{6}$ Optei por citar neste trabalho a autoria de Mistral quando utilizo os textos da publicação organizada por Jaime Quezada. Essa coletânea apresenta o prólogo do organizador e recopila os artigos de Mistral publicados em diversos jornais, reproduzindo as referências de data, etc. Já na coletânea organizada por Roque Esteban Scarpa, optei pela citação do organizador, uma vez que essa publicação reproduz os textos de Mistral, mas no interior de um estudo desse pesquisador sobre o período de Mistral em Punta Arena.

7 Alguns estudos podem ser destacados: PIZARRO, Ana. Gabriela Mistral: el proyecto de Lucila. Santiago, LOM, 2005. FALABELLA LUCO, S. Poema de Chile, sus manuscritos y la valoración del legado de Gabriela Mistral. Estudios Filológicos, n. 46. Santiago, 2010. No Brasil, destaco a pesquisa de SOARES, Gabriela P. A Semear Horizontes: leituras literárias na formação da infância, Argentina e Brasil (1915-1954). Tese (Doutorado em História Social) - Universidade de São Paulo, São Paulo, 2002.
}

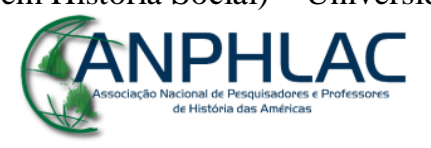

Revista Eletrônica da ANPHLAC, ISSN 1679-1061, №. 24, p. 354-373, Jan./Jun., 2018.

http://revista.anphlac.org.br 
publicando como Lucila Godoy e com pseudônimos diversos. O uso de pseudônimos era comum entre escritoras mulheres ainda no princípio do século $\mathrm{XX}$, sobretudo quando representavam uma opinião dissidente e questionavam o tradicional papel da mulher (VALENZUELA, 2001, p. 2). A partir de 1904, apareceram seus primeiros escritos com pseudônimos de "Alguien" e "Soledad" nos jornais La Voz del Elqui e El Coquimbo.

$\mathrm{Na}$ região de Coquimbo, o jornal que levou o nome da cidade, nos primeiros anos do século XX, era dirigido por Bernardo Ossandon, professor e um dos membros da Assembleia Radical de La Serena desde 1871, que também emprestava livros para a jovem Lucila (ZEGERS, s/d, p. 8). O jornal representava um espaço de discussão mais aberto e liberal onde Gabriela Mistral pode iniciar suas primeiras publicações. Nesse mesmo período, Mistral também publicou no jornal radical La Voz del Elqui.

Lucila Godoy começava então a construir a figura de Gabriela Mistral. Em junho de 1908, usa, pela primeira vez, o pseudônimo Gabriela Mistral no jornal La Constitución del Ovalle. Um mês depois, faz uso do pseudônimo, porém introduz modificações, assinando Mystral com y. A jovem poetisa volta, em julho, a assinar como Mistral no jornal El Coquimbo. Tudo indica estar ensaiando a definição de um pseudônimo (MANZANO, 2008, p. 10). Posteriormente, quando vai viver em Antofagasta, trabalhando como professora de história e inspetora no Liceu dessa cidade, passou a assinar seus trabalhos literários com o nome Gabriela Mistral (TEITELBOIM, 1991, p. 49). A escolha do nome foi inspirada no poeta italiano Gabriele D'Annunzio, que se fez conhecido pelo culto ao primitivo e selvagem, e com sua linguagem voluptuosa. Por outro lado, o poeta francês Federico Mistral, prêmio Nobel de literatura em 1904, terá sobre Mistral uma influência mais significativa. O escritor francês fazia uso em suas obras da língua occitana da Provença. O tributo realizado por Lucila abrange o emprego do nome em seu pseudônimo e, posteriormente, ao criar a revista Mireya (1919), cujo título inspirava-se na obra Mireia de Federico Mistral.

É forçoso observar que a jovem escritora ingressava nas letras a partir de um lugar social muito particular. Em primeiro lugar, deve-se considerar sua juventude no momento de ingresso, ainda ou sobretudo, quando as primeiras publicações eram realizadas em um local e em meios impressos periféricos. Em segundo lugar, sua entrada se fez a partir da pobreza, sem educação formal e como mulher (LUCO, 2013,

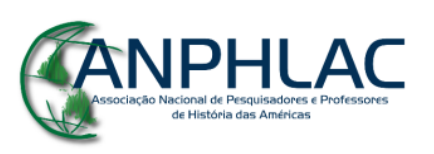

Revista Eletrônica da ANPHLAC, ISSN 1679-1061, №. 24, p. 354-373, Jan./Jun., 2018.

http://revista.anphlac.org.br 
p. 62). Nesse início do século XX, a imprensa, de modo geral, era um espaço privilegiadamente masculino. Deve-se considerar que, no Chile, desde o século XIX, a construção do Estado-Nação se faz por meio de uma hierarquização dos sujeitos sociais e exclusão de uma extensa camada de homens e mulheres que não obedeciam aos prérequisitos de cidadania, os quais não eram considerados como sujeitos portadores de direitos (MIRANDA, 2004, p. 97).

Não é casual o fato de Mistral conseguir publicar nestes jornais, que eram órgãos do Partido Radical. Em 1863, realizou-se no Chile, em Copiapó, cidade a 300 quilômetros mais ao Norte da região de Coquimbo, a primeira assembleia do partido. Este se caracterizou por representar uma posição laica contra setores oligárquicos que dominavam a política chilena desde sua independência. Eram grupos sociais ligados à indústria, ao comércio e à mineração, a funcionários públicos e profissionais, sobretudo nas capitais, que encontravam nos princípios doutrinários liberais radicais a expressão de seus interesses. Durante os anos 1850-60, no governo de Manuel Montt, quando os liberais se aproximam de setores mais conservadores, traindo, para alguns, os princípios especialmente políticos do liberalismo, que assumia uma postura pragmática, segmentos fieis aos princípios sobretudo laicos do liberalismo fundam o Partido Radical em 1863. Propugnavam pela separação entre Igreja e Estado, matrimônio civil, liberdade do sufrágio, educação laica e gratuita e igualdade para as mulheres (MILOS, 2008, p. 16).

Não obstante a exclusão das mulheres do direito ao espaço público, a atuação destas no Chile foi bastante expressiva no jornalismo feminino desde inícios dos anos 1900, quando se verificava uma diversificação social da voz feminina. Estudos recentes identificam, entre os anos de 1900 a 1930, 17 jornais dirigidos por mulheres, sete revistas, além de duas nas quais não se identifica a direção, mas a participação das mulheres é muito expressiva. São claras as definições relacionadas às origens sociais ou aos postulados ideológicos defendidos pelas mulheres editoras. Nos periódicos criados e dirigidos por mulheres trabalhadoras, questiona-se abertamente o papel atribuído à mulher nessa ordem social. Nos periódicos dirigidos por mulheres da elite, a contestação da ordem é menos frequente, porém a própria escrita constitui elemento de transgressão (VALENZUELA, 2001, p. 2). Comuns entre as mulheres que escreviam na imprensa nesse período eram o anonimato e o uso de pseudônimos quando a matéria tratada representava uma contestação mais aberta de seu lugar na sociedade.

\section{GANPHLAC}

Revista Eletrônica da ANPHLAC, ISSN 1679-1061, №. 24, p. 354-373, Jan./Jun., 2018.

http://revista.anphlac.org.br 
Gabriela Mistral construía, portanto, sua voz num espaço de transgressão. A proposição deste estudo é de que Gabriela Mistral constrói essa trajetória conscientemente, testando e desafiando suas possibilidades. Em seu Diario Íntimo, as primeiras anotações datadas de 1905 demarcam claramente o sentido que pretendia dar a sua escrita: "Instruir a la mujer es hacerla digna y levantarla. Abrirle un campo más vasto de porvenir, es arrancar a la degradación a muchas de sus víctimas" (MISTRAL, 2002, p. 29).

No horizonte liberal que a jovem República pautava como modelo a seguir, a sociedade chilena de inícios do século XX se defrontava com os paradoxos formados ao longo da breve construção do Estado-Nação desde o século XIX. Os progressos materiais provindos da exploração do salitre e carvão no Norte do Chile garantiam a riqueza e prosperidade de uma pequena elite industrial em detrimento de uma população de trabalhadores que vivia em situação de extrema pobreza. Os trabalhadores mineiros estavam submetidos a condições de trabalho extremas e insalubres (SUTIL, 2001, p. 50). Por sua vez, o Estado era o grande facilitador da indústria mineira que, desde 1880, representava uma importante e robusta fonte de recursos necessários para as obras de infraestrutura viária que permitiu o desenvolvimento da agricultura e mineração. $\mathrm{O}$ crescimento das atividades mineiras transformou profundamente a sociedade ao gerar um processo migratório de trabalhadores para as cidades do norte e transformações das relações sociais.

A fratura da sociedade, com sua longa história, apresentava, nos albores do século $\mathrm{XX}$, as características de um processo de modernização capitalista que negava aos novos sujeitos sociais espaços de legitimidade e reconhecimento (RIVERA, 2007, p. 81). Em 1900, abre-se no Chile um ciclo de intensos protestos sociais que colocaram em xeque a capacidade das elites de fornecer uma resposta à crise no país. O Chile é sacudido pelos protestos em Valparaíso em 1903, Santiago em 1905, Antofagasta em 1906 e Iquique em 1907. A historiografia chama a atenção:

Una 'sociedad popular' que hacia 1900 enfrenta una de sus más agudas crisis históricas, cuando los caminos de subsistencia peonal se agotaban, los artesanos veían limitadas sus potencialidades de desarrollo y los obreros hacían frente a la soberanía y la indolencia de los empleadores y del Estado, que no querían ver la profundidad social que alcanzaba la crisis de la subsistencia popular. (DURÁN, 2003, p. 10)

\section{GANPHLAC}

Revista Eletrônica da ANPHLAC, ISSN 1679-1061, №. 24, p. 354-373, Jan./Jun., 2018.

http://revista.anphlac.org.br 
Foi precisamente nesse período e numa região de formação social heterogênea e dinâmica que a jovem Lucila Godoy iniciou sua trajetória intelectual. Os primeiros escritos são motivo de acusações e marginalização. Em 1905, decide se formar como professora solicitando a entrada na Escola Normal de La Serena, onde será rejeitada. Para se manter, um amigo conseguiu com que fosse contratada como secretária e assim também pudesse assistir às aulas. Anos mais tarde, Mistral escreveria sobre o tema numa carta a Pedro Aguirre Cerda. Segundo afirma, foi acusada de ateísmo e tendências socialistas pelo fato de ter ajudado meninas pobres a ingressar no Liceu (TEITELBOIM, 1991, p. 48). A rejeição transformou-a em uma disciplinada estudiosa autodidata que continuou a ser ajudada pela franca abertura da biblioteca de Bernardo Ossandon. Cinco anos depois, em 1910, após seus estudos autodidatas, presta exame na Escola Normal n. 1 de meninas em Santiago e obtém o título de professora. Como professora, percorreria algumas cidades, entre elas, Antofagasta, em 1911, cinco anos após os protestos populares que sacudiram a região (1906).

\section{A questão agrária e indígena}

Gabriela Mistral, após obter o título de professora, percorrerá o Chile, trabalhando em várias localidades rurais e pequenas cidades além de manter sua escrita poética. Através de cartas, inicia contatos com outros escritores latino-americanos, enviando, nessas correspondências, poemas que serão conhecidos no México, na Espanha, e no Brasil. É importante lembrar que, somente em 1922, ela publicou seu primeiro livro de poemas, Desolación. Nesses anos, além das publicações e da intensa correspondência que mantém com editores de revistas e jornais e intelectuais, Mistral desenvolve um importante trabalho como educadora, atenta à necessidade de bibliotecas, da criação de cursos noturnos para trabalhadores e especialmente de escolas rurais. Essas preocupações estarão expressas nos escritos de Mistral. Sua experiência ao percorrer o território chileno, nas regiões rurais, tanto no norte como no sul do Chile, deu-lhe um profundo conhecimento sobre a realidade do campo e da pobreza. Sua intervenção no debate público em torno dessas questões sociais levou-a ao México para colaborar com o governo em virtude da sua experiência pedagógica nos pequenos povoados rurais da região de Coquimbo como professora e como diretora de escolas de

\section{CANPHLAC}

Revista Eletrônica da ANPHLAC, ISSN 1679-1061, №. 24, p. 354-373, Jan./Jun., 2018.

http://revista.anphlac.org.br 
regiões provinciais em Punta Arenas, no sul do Chile, e Temuco, ao norte (SCHNEIDER, 1997, p. 147). Um dos temas centrais neste momento é a questão agrária. Essa preocupação intelectual e política esteve presente ao longo de sua vida errante antes mesmo de partir para o México e nos escritos posteriores que continuaria a publicar em diversos jornais da América Latina. ${ }^{8}$ Constantemente, reafirmava sua postura de intervenção nos temas de importância nacional para o Chile como a defesa da lei de instrução primária obrigatória, educação científica para mulheres, educação para os povos originários e operários, introdução da temática ambiental, etc. (ORELLANA; ZEGERS, 2008, p. 46). As notas sobre a questão agrária serão frequentes. A experiência no México, mais do que tudo, aprofundou suas convicções. Gabriela Mistral afirmaria, em seu Diário Íntimo, num período maduro de sua vida, já prêmio Nobel, nos anos 1950:

Yo soy una vieja agrarista y creo que una reforma agraria hará feliz al pueblo campesino que es el que más quiero en cualquiera parte del mundo. [...]Yo soy una vieja agrarista porque fui una niña del campo y vi el egoísmo y la estupidez de dos aldeas: ni un solo campesino con tierra. Tres haciendas dueñas del suelo y hasta del mujerío que los patrones se adjudicaban. La suerte del aldeano y de las mujeres rurales no solo me toca, me sacude. (MISTRAL, 2002, p. 213)

A preocupação de Mistral com a questão agrária estava relacionada, como se vê, à sua vivência na infância, e estas se adensam com as leituras. Em 1923, escreveria no jornal El Mercúrio, quando vivia no México, artigo intitulado El Presidente Obregón y la situación de México. O relativamente extenso texto pretende expor aos chilenos o significado das reformas que estavam sendo realizadas no México pós-revolucionário sob a liderança, naquele momento, de Álvaro Obregón, presidente eleito duas vezes no México, em 1920-24 e em 1927 até 1928, quando foi morto. ${ }^{9}$

\footnotetext{
${ }^{8}$ MISTRAL, Gabriela. Pasión agraria. El Mercurio, Santiago, 11 de março de 1928; Conversando sobre la tierra. Repertório Americano, Tomo 23, San José, Costa Rica, 19 de setembro 1931; El Pueblo Arauco. La Nación, Buenos Aires, 17 de abril de 1932. In: QUEZADA, J. (Org.). Gabriela Mistral. Escritos Políticos. Santiago, FCE, 1994.

9 Álvaro Obregón procura atender algumas demandas de Reforma Agrária presentes na Revolução Mexicana de 1910. Nesse sentido, emitiu leis que regulamentavam artigos constitucionais sobre as terras comunais. A Ley de Ejidos de 1920 foi substituída pelo Reglamento de abril de 1922, que fixava a extensão das parcelas e as formas para obtenção de terras. Ele representava o grupo político do estado de Sonora, que consegue por fim, parcialmente, no conflito armado. Deu início também à importante reforma da educação com José Vasconcelos. Ver: SANTANA, Laura. Legislación e instituciones agrarias en México (191-1924). ACHSC, vol. 40, n. 1, jun. 2013, Colombia, p. 273-197.
}

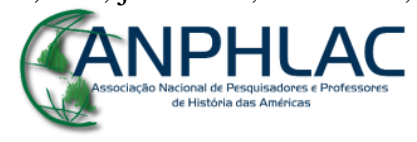

Revista Eletrônica da ANPHLAC, ISSN 1679-1061, №. 24, p. 354-373, Jan./Jun., 2018.

http://revista.anphlac.org.br 
$\mathrm{O}$ artigo sublinha os diversos pontos desse processo de transformações no México, desde a Reforma Agrária à reforma na educação. Mistral, entretanto, quer acentuar o sentido de modelo da Reforma Agrária para o resto da América Latina. Suas palavras são enfáticas: "Se inicia em "Nossa América" a reforma agraria que passará aos outros países" (MISTRAL, 1994, p. 240). ${ }^{10}$

O texto escrito em 1923 é relembrado posteriormente em 1928 quando analisa o que ela chamava de "agrarismo" chileno. Nele, insiste sobre a necessidade de uma reforma agrária no Chile, nomeia o que chama de "nosso feudalismo rural", referindo-se ao latifúndio e à condição de submissão do camponês. Aponta a "los patrones", como ao latifundiário, que formam parte do Congresso e que manejam a opinião na imprensa, que defendem interesses abusivos. Mistral cobra deles que seja resolvido o problema "perversamente postergado" da propriedade rural.

Mas o problema agrário para Mistral não se reduz à posse da terra. Para ela, é preciso compreender o significado dessa terra para o camponês e o indígena. A memória serve aqui como elemento de conexão essencial. Será sua experiência, sempre retomada, de vivência no campo que lhe permite, em seu discurso, repor os significados da realidade do homem do campo no Chile de inícios do século XX. Contestando as afirmações repetidas na imprensa, entre intelectuais e políticos no Chile, que consideravam o alcoolismo como a principal causa da destruição indígena, Mistral aponta como o povo araucano foi "enlouquecido" e "barbarizado" pelo despojo de sua terra. Mas, para entender essa afirmação, seguindo seu pensamento, é preciso saber o que significa a terra para "el índio". Se, para nós, ela é um bem entre outros, para ele, a terra é:

[...] Su alfa y su omega, el asiento de los hombres y el de los dioses, la madre aprendida como tal desde el gateo del niño, algo como una esposa por el amor sensual con que se regodea, y la hija suya por siembras y riesgos. Estas emociones se trenzan en la pasión profunda del indio por la tierra. (MISTRAL, 1994, p. 48)

Para Mistral, o tema da reforma agrária não surge como uma proposta impensada ou apenas consequência da sensibilidade e experiência da infância, mas também como fruto de estudos cuidadosos, de seu autodidatismo. Ao percorrer seus

\footnotetext{
${ }^{10}$ A referência a "Nossa América" não é despropositada. Mistral escreverá posteriormente dois artigos dedicados a José Martí em 1932 no jornal El Mercúrio onde se referia a ele como "el maestro americano" (MISTRAL, 1994, p. 214).
}

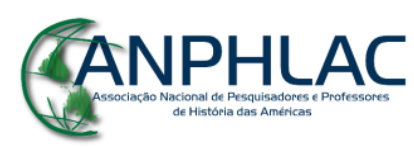


escritos, os indícios de leituras são abundantes. Dizia em 1928: “Acabo yo de leer una bella obra sobre la reforma agraria en Europa, y salgo de esa lectura reconfortante con una enorme humillación respecto de la América" (MISTRAL, 1994, p. 51). Sua análise sobre a realidade do problema da terra no Chile parte de uma reflexão e comparação sobre outras experiências de reforma agrária.

A América Latina, no início do século XX, conheceria um dos momentos mais marcantes da experiência de luta pela terra, com a Revolução Mexicana de 1910. Nas reflexões de Mistral, o estudo dessa realidade agrária representava um momento de inflexão. Entre 1922-24, a escritora viveu no México, participando do projeto educacional pós-revolucionário, como dito anteriormente, quando toma parte da organização de bibliotecas populares. Este trabalho coloca em destaque suas preocupações centrais: o compromisso enquanto intelectual com os problemas da desigualdade e da educação. Aqueles anos foram dedicados ao estudo dessa realidade e a uma verdadeira investigação que a levaria a percorrer o país. José Vasconcelos (18821959) escreveria mais tarde, falando da estadia de Mistral no México:

[...] pasando temporadas cortas en la capital, dirigía sus actividades por distintos rumbos del país. [...] Así por ejemplo, al llegar a una aldea y recordando, quizás, cierta costumbre árabe, dedicábase, por las tardes, a leerles a la gente el periódico, desde su púlpito: un banco de la plaza...Esto provocaba polémicas, establecía relaciones y creaba amistades, entre el maestro y la población. De allí venía el pedido de libros, la fundación de una pequeña biblioteca [...]. (SCHNEIDER, 1997, p. 153)

Convidada a passar três meses no México, seu trabalho e interesse prolongaram a estadia por dois anos. Suas viagens pelo interior do México não apenas dão a conhecer os problemas da educação no país, mostram igualmente, no olhar de Mistral, que estes estavam relacionados à questão agrária: o sentido da terra, a cultura camponesa e indígena, o universo simbólico que organizava a vida comunitária dos pequenos povoados, as relações de reciprocidade e solidariedade que construíam a vida das pessoas no campo. As noções que Mistral trazia de sua experiência de infância no Chile foram enriquecidas no México. Daí extrai alguns dos elementos para suas reflexões sobre o problema agrário no Chile, acrescidos dos estudos aos quais se dedica permanentemente.

\section{CANPHLAC}

Revista Eletrônica da ANPHLAC, ISSN 1679-1061, №. 24, p. 354-373, Jan./Jun., 2018.

http://revista.anphlac.org.br 
Em cada texto, robustece seu argumento de crítica política ao latifúndio. Em 1925, escreve sobre a seca na região de Coquimbo, ao norte do Chile. A região é sempre lembrada na imprensa da época por seu porto, entretanto Mistral destaca a "epidemia de fome" e emigração que atingiu a região rural naquele ano de seca. Frente à calamidade, a sociedade na província mobilizou-se em torno da caridade e ajuda. Sem negar a importância dessa solidariedade, para a escritora, entretanto, prevalece o sentido de casta e exclusão que o latifúndio estabelece desde a colônia. Mistral contestava o argumento que os grandes proprietários repetiam na imprensa sobre a impossibilidade de dividir a terra em pequenas propriedades, uma vez que os camponeses eram incapazes de organizar sociedades e cooperativas e empreender obras como canais de irrigação, etc. A carestia resultante da seca era atribuída a um espírito pouco empreendedor e totalmente passivo do camponês chileno. Mistral, entretanto, contesta, demonstrando a tese inversa de que, por um lado, essas regiões foram dominadas pelo latifúndio e, por outro, os salários iníquos impossibilitaram qualquer tipo de projeto técnico capaz de fazer frente às estiagens da região. Seus textos jornalísticos são breves, porém pretendem ser rigorosamente militantes, denunciando as causas dos problemas sociais da região.

A preocupação de Mistral com a questão e seu envolvimento vigoroso no debate da época tiveram, ao que tudo indica, uma relevância singular expressa na dedicatória que Aguirre Cerda dedica à poetisa em seu livro El Problema Agrário, publicado em 1929. O livro pretende fazer uma análise das experiências agrárias em diversos países no qual se debate os tipos de propriedade, as formas de exploração, a educação agrícola, o crédito agrícola, a organização de associações e cooperativas, etc. Sua análise pretende estabelecer os critérios de uma reforma agrária no Chile. Esta seria uma das bandeiras da Frente Popular, aliança dos partidos Socialista, Comunista e Radical, que elege Aguirre Cerda como presidente do Chile em 1938.

Uma lei de Reforma Agrária só seria aprovada pelo Congresso chileno em 1962 com Jorge Alessandri (1958-64) ${ }^{11}$. Entretanto, a discussão sobre os problemas sociais e políticos decorrentes da grande propriedade da terra e a situação de pobreza extrema do homem do campo e o consequente processo migratório alcançam destaque na imprensa chilena nos primeiros anos do início do século $\mathrm{XX}$ quando se debate a chamada

\footnotetext{
${ }^{11}$ Jorge Alessandri se elege como candidato independente, porém com o apoio dos Partidos Conservador, Liberal e Radical.
}

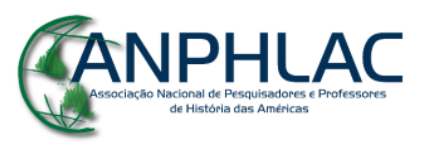

Revista Eletrônica da ANPHLAC, ISSN 1679-1061, №. 24, p. 354-373, Jan./Jun., 2018.

http://revista.anphlac.org.br 
“questão social". A formação intelectual de Mistral deu-se nesse contexto de intensas transformações em que se deve destacar uma politização da diferença entre ricos e pobres (PINTO, 1997, p. 2). Dessa maneira, e considerando que os primeiros textos de Mistral sobre a questão da terra são produzidos nos anos 1920, deve-se reconhecer o importante e destacado papel desempenhado por essa escritora, ocupando um lugar definitivo como mulher e como intelectual no debate sobre a realidade social chilena.

\section{A Educação Popular e a mulher}

No seu trabalho como educadora e nos seus escritos dos primeiros anos, Mistral demonstrará que uma das suas mais fortes preocupações será com o problema da educação popular e das mulheres.

Em 1910, após receber seu diploma de professora, começa a exercer a profissão em distantes localidades do país. Primeiramente, é designada como professora, na escola rural de Barrancas, em Santiago, depois em Traiguén, na região da Araucania. Daí é enviada para o norte do Chile para ocupar o cargo de professora de Geografia e História (1911). No ano seguinte, vai para o Liceu de Los Andes para atuar como inspetora e professora de Geografia e Espanhol, onde permanece até 1918 quando é nomeada para a direção de Liceu de Meninas em Punta Arenas. Diferentemente das experiências anteriores, essa função permitir-lhe-á realizar um importante trabalho como educadora e intelectual, já que disporá de maior capacidade decisória.

Nesse período, será também bastante intenso seu trabalho de escrita. Além de manter correspondência com diversos escritores e contribuir com publicações como Elegancias (1911-14), dirigida por Rubén Darío ${ }^{12}$, criara a revista Mireya com Julio Munizaga Ossandón.

A nomeação de Mistral para o Liceu de Punta Arenas busca atender à indicação do Ministério da necessidade de reforma dos Liceus (SCARPA, 1977, p. 112). Um levantamento das condições de saúde das crianças apontou altas porcentagens de crianças com tuberculose, raquitismo ou debilidade geral. Mistral procurou resolver estes e outros problemas como melhorar as condições das salas de aula e aumentar o

\footnotetext{
${ }^{12}$ Rubén Darío (1867-1916), poeta nicaraguense que consagra o Modernismo literário espanhol.

\section{GANPHLAC}

Revista Eletrônica da ANPHLAC, ISSN 1679-1061, №. 24, p. 354-373, Jan./Jun., 2018.

http://revista.anphlac.org.br
} 
número delas, uma vez que haviam crescido os números de matrículas e a assistência diária (SCARPA, 1977, p. 136).

A atividade desenvolvida em Magallanes por Mistral permitirá concretizar algumas de suas ideias já propaladas sobre a importância da educação das mulheres e, especialmente, das mulheres do povo. Em setembro de 1918, Mistral realizará uma conferência na Sociedad de Instrucción Popular de Magallanes, inaugurando o projeto de Escola Noturna Popular voltado para a instrução feminina. Sua conferência foi reproduzida no jornal El Magallanes. Mistral afirmava:

La Sociedad de Instrucción Popular abre unos cursos nocturnos de mujeres, y esto es de una inmensa significación para nuestra ciudad. Se trata de la primera escuela de tal índole que habrá en provincias. Es una honra para el grupo de mujeres que busca más amplitud de horizontes y muy principalmente para la institución que recoge la voz de los humildes. (SCARPA, 1977, p. 147)

A Sociedad de Instrucción Popular, como demonstra a recente historiografia ${ }^{13}$, foi uma instituição inaugurada em Valparaíso e Santiago em meados do século XIX, e que funcionava em todo o país. Organizada por liberais, seguindo o modelo de beneficência das elites, procurava reforçar a educação estatal. A noção de Instrucción popular era, no caso, divergente da autoeducação proletária, que nasce no seio da própria classe operária e tem um sentido libertário. A noção que fundamentava a Sociedad de Instrucción Popular era especificamente orientada pelas classes dominantes e visava a um disciplinamento e chilenização em todo o território nacional, especialmente no caso das regiões de fronteira ao norte ou sul do país.

Gabriela Mistral, como diretora de escola e conferencista nessa sociedade, procura dar proeminência ao que considerava fundamental, que era a educação da mulher, e, neste caso, da mulher operária. Mistral acentua sua compreensão da caridade e o sentido que atribui à educação da mulher. $\mathrm{O}$ destaque deixa ver a resistência da sociedade à aplicação desses recursos na educação da trabalhadora. Enquanto, segundo diz, estendem-se por todo o país as escolas noturnas para trabalhadores, a mulher fica desassistida e "tacitamente condenada a não se incorporar jamais às atividades humanas mais nobres" (SCARPA, 1977, p. 147).

\footnotetext{
${ }^{13}$ LARA, José J. Soto; ZÚÑIGA, P. Chaves. El nacionalismo de la "Sociedad de Instrucción Pública" de Arica (1914-1925). Cuadernos Chilenos de la Historia de la educación. Santiago, n. 5, marzo de 2016.
}

\section{GANPHLAC}

Revista Eletrônica da ANPHLAC, ISSN 1679-1061, №. 24, p. 354-373, Jan./Jun., 2018.

http://revista.anphlac.org.br 
Ao elencar os temas levantados por Mistral em sua fala, denota-se sua tentativa de dar respostas às críticas ao projeto. As críticas eram as seguintes: perigo do feminismo ${ }^{14}$ entre as mulheres; o desrespeito às hierarquias sociais ao misturar mulheres de classe média com mulheres do povo. Consideravam dispensável a educação de mulheres do povo e viam com desconfiança o uso de tempo de descanso das trabalhadoras para o estudo de pouca utilidade. No discurso, Gabriela Mistral aponta para os princípios republicanos que deveriam prevalecer numa escola e que, portanto, nela não devem ser reproduzidas as hierarquias e distinções sociais:

He hablado especialmente de mujeres del pueblo; nuestra matrícula tiene también varias de la clase media. La asistencia común a un templo de gentes de distinta condición no degrada a nadie, porque la escuela es la negación de las castas si es cristiana de verdad y si educa mujeres de una república de verdad también. (SCARPA, 1977, p. 150)

No período em que Gabriela Mistral vivia em Punta Arenas, após um longo debate no Congresso e na imprensa, foi aprovada e publicada, em 26 de agosto de 1920, a Lei de Educação Primária Obrigatória que, como diz em seu título, tornava obrigatória a educação dos primeiros quatro anos escolares, a qual devia ser de responsabilidade do Estado e dos municípios, mantendo ainda a gratuidade para ambos os sexos, responsabilidade e gratuidade que haviam sido estabelecidas em lei de $1860 .{ }^{15}$

No momento em que a lei foi despachada pelo Congresso, em 1919, Mistral escreveria, em sua Revista Mireya, um artigo onde elabora um duro diagnóstico diante da frustrada resposta dada pelo Congresso chileno às demandas da sociedade ao longo de cinco anos de debates. Primeiramente, a escritora destaca a mobilização dos trabalhadores, das sociedades de professores e da imprensa como um todo na reivindicação da responsabilidade do Estado pela educação primária obrigatória. Em seguida, destaca a burla que essa lei representa. Em seu vocabulário, está explícita a apreciação do que significava a lei: desmoralizadora, ridícula, uma injúria, vergonhosa,

\footnotetext{
${ }^{14}$ Não apenas Gabriela Mistral se refere ao feminismo como circula em Santiago em 1922 a revista Acción Femenina, órgão do primeiro partido político de mulheres chamado Partido Cívico Femenino fundado em 1922. Nela, encontram-se artigos com títulos como o seguinte: "¿Qué clase de feminismo defendemos y por qué?", dando provas da circulação e da discussão do seu significado (MIRANDA, C. 2004).

${ }^{15}$ Ley 3.654 sobre Educación Primaria Obligatoria. Publicada en Diario Oficial 12.755 de 26 de agosto de 1920. Santiago de Chile, Imprensa Lagunas \& Cia. 1921. Disponível em: www.memoriachilena.cl Acesso em: $26 / 11 / 2016$.
}

\section{CANPHLAC}

Revista Eletrônica da ANPHLAC, ISSN 1679-1061, №. 24, p. 354-373, Jan./Jun., 2018.

http://revista.anphlac.org.br 
"mácula nacional". A partir da questão dos baixos salários que a lei estabelece para o professor rural, Gabriela desenvolve seu argumento apontando o denotado desprezo das classes altas e médias pela educação primária no Chile. Diz ela: "la indiferencia por la escuela está en el ambiente: de él lo han recogido los legisladores" (SCARPA, 1977, p. $180)$.

A discussão não era nova para Mistral. Em 29 de dezembro de 1908, no jornal La Voz del Elqui, havia escrito o artigo intitulado "Sobre la Instrucción Primaria Obligatoria" (SCARPA, 1977, p. 181). Nele, já defendia a imperiosa necessidade da obrigatoriedade da educação primária nas regiões rurais do Chile, onde as condições de pobreza eram extremas. A obrigatoriedade implicava atribuir ao Estado a responsabilidade em fornecer condições adequadas para o ensino, criando os estabelecimentos e contratando professores. No projeto aprovado em 1920, ficavam estabelecidos mecanismos de controle com inspetores que deviam zelar pelo cumprimento da frequência dos alunos, das condições das escolas, etc. Esses inspetores finalmente terminavam por fornecer as informações sobre escolarização e índices de analfabetismo no país.

A figura de Mistral costuma ser pensada a partir de sua consagrada vida literária. Entretanto, chama a atenção em sua biografia o percurso de intelectual que antecede e configura sua consagração literária. Ao transitar em dois mundos, o daqueles professores missioneiros, como entendia José Vasconcelos (FELL, 2009), que percorrem o país em suas entranhas, nos pequenos povoados e o das letras consagradas, ela se torna uma intelectual paradigmática para pensar essa complexa relação do intelectual na América Latina. O trânsito que faz entre a cultura erudita e popular, sua militância intelectual e sua inscrição nos projetos de promoção rural propostos por José Vasconcelos entre 1921-24 ensejam novos olhares que certamente poderiam elucidar melhor sua poesia.

Nos limites deste artigo, a proposta foi examinar a imbricada e inseparável relação do intelectual enquanto criador e mediador cultural. A noção de intelectual mediador opera em primeiro lugar com o conceito de intelectual delineado por Sirinelli (2003), como categoria socioprofissional que surge a partir do caso Dreyfus. Esses sujeitos históricos, fazendo uso de seu lugar destacado e reconhecido no campo da cultura, buscam afirmar e legitimar uma posição no debate público. Por outro lado,

\section{GANPHLAC}

Revista Eletrônica da ANPHLAC, ISSN 1679-1061, №. 24, p. 354-373, Jan./Jun., 2018.

http://revista.anphlac.org.br 
destaca-se aqui o fenômeno da mediação cultural, ou seja, comunicação e circulação de bens culturais como processos complexos e inseparáveis da produção e criação de significados (GOMES, 2016). Nesse sentido, Gabriela Mistral se apresenta como sujeito histórico que permite refletir sobre o intelectual e o entrelaçamento entre produção, criação e mediação cultural.

\section{Referências bibliográficas}

ARAYA, G. Juan Gabriel. Gabriela Mistral y el recado. Horizontes Educacionales, Universidad del Bío Bío, Chillan, Chile, 2000.

BLANCO, Pablo Toro. El partido radical: notas sobre una nueva forma de sociabilidad política en Chile del siglo XIX. História, Santiago, v. 28, p. 299-310, 1994. Disponível em: http://revistahistoria.uc.cl/wp-content/uploads/2011/10/toro-pablo-28.pdf Acesso em: 16/06/2017.

BUNGE, Carlos Otávio. La Educación. Madrid: La España Moderna, 1902.

BOURDIEU, P. A ilusão biográfica. In: AMADO, Janaina; FERREIRA, Marieta M. (Org.). Usos e abusos da história oral. Rio de Janeiro: Fundação Getúlio Vargas. 1998.

Economia das trocas simbólicas. São Paulo: Perspectiva, 2009.

CERDA, Aguirre. El Problema Agrario. Paris: 1929. Disponível em: http://www.memoriachilena.cl/602/w3-article-7793.html Acesso em: 06/07/2017.

CRESPO, Regina. O projeto educativo de José Vasconcelos no México pósrevolucionário: nacionalismo e modernidade. Intellèctus, Ano XV, n. 2, Rio de Janeiro, 2016.

DOMINGUÉZ, Matías T. Gabriela Mistral y Pedro Aguirre Cerda través de su correspondencia privada (1919-1941). Historia, Santiago, v. 35, 2002.

FELL, C. José Vasconcelos, los años del águila (1920-1925): Educación, cultura e iberoamericanismo en el México posrevolucionario. México: UNAM, 2009.

GARCÍA REY, R. La presencia de América Latina en El Maestro, 1921. Revistas Literarias y culturales. CIAL. UNAM, México, s/d. Disponível em: http://www.cialc.unam.mx/Revistas_literarias_y_culturales/PDF/Articulos/La_presenci a_de_america_latina_en_el_maestro.pdf Acesso em: 25/08/2017.

GARCÉS DURÁN, Juan. Crisis social y motines populares en el 1900. Santiago: LOM Ediciones, 2003.

GOMES, Ângela de C.; HANSEN, Patrícia S. Intelectuais, mediação cultural e projetos políticos: uma introdução para a delimitação do objeto de estudo. In: GOMES, Ângela

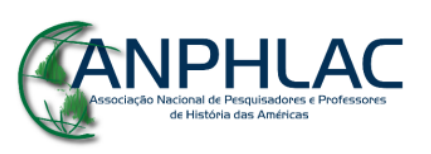

Revista Eletrônica da ANPHLAC, ISSN 1679-1061, №. 24, p. 354-373, Jan./Jun., 2018.

http://revista.anphlac.org.br 
de Castro; HANSEN, Patrícia S. (Orgs.) Intelectuais mediadores. Práticas culturais e ação política. Rio de Janeiro: Civilização Brasileira, 2016.

HUTT, Claudia Cabello. Gabriela Mistral: artesana de sí misma: multifuncionalidade de la prosa mistralina en su construcción como sujeto intelectual. Taller de Letras, Santiago, n. 41, 2007. Disponível em: http://letras.uc.cl/html/6_publicaciones/pdf_ revistas/taller/t141_3.pdf Acesso em: 22/07/2017.

LUCO, Soledad Falabella. Gabriela Mistral y Winétt de Rokha: género, discurso, sexualidad y cultura letrada pública a principios del siglo XX en Chile. In: MELO, A. A. M. C.; OLIVEIRA, I. T. (Orgs.). Aproximações: cultura e Política. Fortaleza: Expressão Gráfica, 2013.

MANZANO, Rolando. Recorrer la vida desde la vereda contraria. Património Cultural, DIBAM, Santiago, n. 46, año XIII, 2008.

MILOS, Pedro. Frente Popular en Chile. Su configuración: 1935-1938. Santiago: LOM, 2008.

MIRANDA, Claudia Monteiro. Tensiones en la trastienda: una aproximación teórica a lo público y lo privado en el feminismo. Chile 1922. Clio, Nueva Época, Santiago, v. 4, n. 32, 2004.

MISTRAL, Gabriela. José Martí (II). In: Quezada, J. (Org.). Gabriela Mistral. Escritos Políticos. Santiago: FCE, 1994.

El Pueblo Arauco. La Nación, Buenos Aires, 17 de abril de 1932. In: QUEZADA, J. (Org.). Gabriela Mistral. Escritos Políticos. Santiago: FCE, 1994.

Agrarismo en Chile. El Mercurio, Santiago, 23 de setembro de 1928. In: QUEZADA, J. (Org.). Gabriela Mistral. Escritos Políticos. Santiago: FCE, 1994.

Una provincia en desgracia: Coquimbo. Santiago. El Mercurio, 13 de septiembre de 1925. In: QUEZADA, J. (Org.). Gabriela Mistral. Escritos Políticos. Santiago: FCE, 1994.

Pasión agraria. El Mercurio, Santiago, 11 de março de 1928. In: QUEZADA, J. (Org.). Gabriela Mistral. Escritos Políticos. Santiago: FCE, 1994.

Conversando sobre la tierra. Repertório Americano, Tomo 23, San José, Costa

Rica, 19 de setembro 1931. In: QUEZADA, J. (Org.). Gabriela Mistral. Escritos Políticos. Santiago: FCE, 1994.

ORELLANA, M.; ZEGERS, P. Lucila Gabriela: la voz de la maestra. Santiago: DIBAM, 2008.

PELLEGRINI, M. Gabriela Mistral: entre el quício y el umbral. Acta Literaria, Concepción, n. 35, p. 29-43, 2007.

\section{GANPHLAC}

Revista Eletrônica da ANPHLAC, ISSN 1679-1061, №. 24, p. 354-373, Jan./Jun., 2018.

http://revista.anphlac.org.br 
PINTO, Julio. ¿Cuestión social o cuestión política? La lenta politicización de la sociedad Tarapaqueña hacia fin del siglo (1889-1900). Historia, Santiago, v. 30, 1997. Disponível em: http://revistahistoria.uc.cl/estudios/2910/ Acesso em: 30/05/2017.

QUEZADA, Jaime. Bendita me lengua sea. Diário Íntimo de Gabriela Mistral. Santiago: Editorial Planeta/Ariel, 2002.

RIVERA, Felipe. Movimiento obrero y modernidad en Chile: una relectura desde la massacre de Santa Maria de Iquique. In: VÁSQUEZ, David. La masacre de la Escuela de Santa Maria de Iquique. Mirada histórica desde la Cámara de Diputados. Santiago: Ediciones de la Biblioteca del Congreso Nacional de Chile, 2007.

SANTANA, Laura. Legislación e instituciones agrarias en México (1910-1924). ACHSC, v. 40, n. 1, jun. 2013, Colombia, p. 273-197.

SOARES, G. Pellegrino. Mestres das primeiras letras como mediadores culturais: escolas rurais e usos da escrita em povoados indígenas do México no século XIX. In: GOMES, Ângela de Castro; HANSEN, Patrícia S. (Org.) Intelectuais mediadores. Práticas culturais e ação política. Rio de Janeiro: Civilização Brasileira, 2016.

SCHNEIDER, Luis Mario. Gabriela Mistral en México. Una devote del misionerismo vasconcelista. In: LILLO, G.; RENART, G. Re-leer hoy a Gabriela Mistral. Mujer, historia y sociedad en América Latina. Ottawa/Santiago: University Ottawa/Universidad de Chile, 1995.

SIRINELLI, Jean François. Os intelectuais. In: REMOND, René. Por uma história política. Rio de Janeiro: FGV, 2003.

SUTIL, Sofia Correa. Historia del siglo XX chileno. Santiago: Editorial Sulamericana, 2001.

TEITELBOIM, Volodia. Gabriela Mistral, pública y secreta. Santiago de Chile: BAT, 1991.

VALENZUELA, Carola Agliati. Explorando un espacio desconocido. Prensa de mujeres en Chile, 1900-1920. Revista de la Facultad de Filosofía y Humanidades, Universidad de Chile, Santiago, n. 19, 2001. Disponível em: http://www.cyber humanitatis.uchile.cl/index.php/RCH/article/view/8789 Acesso em: 10/08/2017.

ZEGERS, Pedro. Gabriela Mistral en El Coquimbo. Vicuña: Dibam, s/d.

Gabriela Mistral en La Voz del Elqui. Vicuña: Dibam, s/d.

\section{GANPHLAC}

Revista Eletrônica da ANPHLAC, ISSN 1679-1061, №. 24, p. 354-373, Jan./Jun., 2018.

http://revista.anphlac.org.br 